\title{
The peculiar case of Lehrer's lawyer
}

\author{
Kevin Wallbridge ${ }^{1}$ (D
}

Received: 11 May 2016 / Accepted: 25 November 2016 / Published online: 18 December 2016 C The Author(s) 2016. This article is published with open access at Springerlink.com

\begin{abstract}
The peculiar case of Lehrer's lawyer purports to describe a scenario in which a subject has a justified belief, indeed knowledge, despite the fact that their belief is not causally or counterfactually sustained by any good reasons for it. The case has proven controversial. While some agree with Lehrer's assessment of the case, others disagree, leading to a schism among accounts of the basing relation. In this paper I aim to reconcile these camps and put simple causal and counterfactual accounts of the basing relation back on the table, by arguing that Lehrer's case is probably metaphysically impossible, but even if it isn't, it is ambiguous between a psychologically implausible and a psychologically plausible reading, and this can account for the diverging intuitions that it generates.
\end{abstract}

Keywords Epistemic basing relation - Basing relation - Doxastic justification · Gypsy lawyer

\section{Introduction}

It is a truism that a belief is only justified or knowledge if it is based on the right kinds of reasons or evidence. Unfortunately, there is very little agreement as to what exactly is required for a belief to be based on a particular reason. Early accounts invoked simple causal or counterfactual relations between belief and basis, but in 1971 Lehrer derailed these accounts with an example which he claimed shows a belief that is justified, and

$凶$ Kevin Wallbridge

K.J.Wallbridge@gmail.com

1 University of Edinburgh, School of Philosophy, Psychology and Language Sciences,

Dugald Stewart Building, 3 Charles Street, Edinburgh EH8 9AD, UK 
amounts to knowledge, even though it is not causally or counterfactually related to any good reasons.

Although controversial, many have been persuaded by Lehrer's example and it has shaped the landscape, creating a schism between those who agree with Lehrer's verdict on the case versus those who do not. This has led to a situation whereby it is impossible for any account of the basing relation to gain widespread support, because no account can satisfy both of these factions.

However, I will argue that the importance of Lehrer's case has been overestimated. Given some plausible metaphysical assumptions, the case he describes turns out to be impossible. But even without these assumptions, the case is psychologically highly implausible when understood in the way Lehrer requires. Therefore we can reasonably suppose that intuitions regarding the case diverge because people are in fact considering two different versions of the case: one psychologically plausible, and the other not. But either way, this case does not present a counterexample to causal or counterfactual accounts of epistemic basing.

\section{The epistemic basing relation}

\section{Holmes and Watson investigate}

Holmes believes that the butler did it. In fact, he knows that the butler did it: footprints at the scene show that the culprit had size eleven feet, no-one but the staff were in the house at the time, and the butler is the only one with size eleven feet. Watson has been with Holmes every step of the way and so has seen and heard everything that Holmes has. Watson also believes that the butler did it, but Watson hasn't put the clues together like Holmes has. He believes that the Butler is guilty because he believes in phrenology (contrary to scientific consensus), and concludes that the butler's pointed head and prominent brow are clear signs of his criminal nature.

Holmes and Watson both believe that the butler did it. Moreover, since they have both seen and heard everything necessary to solve the case, they both have evidence proving that the butler did it, so the proposition 'the butler did it' is justified for both of them. But clearly while Holmes knows that the butler did it and his belief to that effect is entirely justified, Watson does not know that the butler did it and his belief to that effect is utterly unjustified. (We can call the sense in which the proposition 'the butler did it' is justified for both of them propositional justification, and the sense in which Holmes' belief is justified, but Watson's is not, doxastic justification. It is the latter kind of justification which matters for present purposes. $)^{1}$

The difference between Holmes and Watson is that Holmes believes for the right reasons, his belief is based on good evidence, whereas Watson believes for the wrong reasons, his belief is based on irrelevant facts about the shape of the butler's skull. The difference is a perfectly commonsensical one and it makes all the difference from an

\footnotetext{
1 This kind of distinction has been made many times, it has been put by saying that a belief can be propositionally justified but not doxastically justified (e.g. Firth 1978), justifiable but not justified (Pollock 1986), justified but not well-founded (Conee 1985), or ex ante justified but not ex post justified (Goldman 1979).
} 
epistemic point of view, since whether a belief is justified and whether it is knowledge depends on what it is based on. ${ }^{2}$ It is therefore unsurprising that epistemologists have put considerable time and effort into trying to work out exactly what this epistemic basing relation consists in. The obvious candidates are some kind of causal or counterfactual relation, along the lines of the following.

Basic causal account

A belief that $\mathrm{p}$ is based on a basis $\mathrm{b}$ iff $\mathrm{b}$ causes, or causally sustains, the belief that $\mathrm{p}$.

\section{Basic counterfactual account}

A belief that $\mathrm{p}$ is based on a basis b iff, if it weren't for $\mathrm{b}$ then you wouldn't believe that $\mathrm{p}$ (or $\mathrm{b}$ is a member of a set B, such that if none of the members of B obtained then you would not believe that $\mathrm{p}$ ).

These basic accounts may require some finessing in order to account for the possibility of deviant causation or counterfactual support, but nonetheless it seems that the basing relation has to be some kind of causal or counterfactual relation. After all, it seems that the basis of a belief is what explains why one believes as one does, and causal or counterfactual facts are the only kinds of things that can capture this explanatory relation. ${ }^{3,4}$

If the story ended there then it would be a happy tale: there is an important epistemic phenomenon (epistemic basing), and it seems that there is an obvious way of spelling out what this amounts to (namely in causal or counterfactual terms), so a satisfactory account of the phenomenon seems close at hand. But unfortunately this is not where our story ends. In 1971, Lehrer proposed a counterexample to the then prevailing causal account of the basing relation, and this example has been causing trouble ever since.

\section{Lehrer's lawyer}

(In what follows, I present a slightly modified version of Lehrer's case, in which the order of events differs slightly. This makes no difference to the substance of the case, but it makes my later exposition easier to state. $)^{5}$

\footnotetext{
2 And beyond epistemology too. It seems like a close analogue is at play when we think about reasons for action: if one's decision to build a windfarm is based on a desire to get filthy rich, then it will be evaluated very differently to if that decision were based on a desire to improve the lives of future generations. Cases like Lehrer's impact on this kind of basing relation too. Kvanvig's (2003) Ill-motivated politician case (which I consider in Sect. 10) is modelled on Lehrer's and applied to reasons for action.

3 Accounts of the basing relation have been given in terms of causal relations (Moser 1989; Goldman 1979), dispositional relations (Turri 2011; Evans 2013), counterfactual relations (Swain 1981; Bondy 2015, and doxastic relations, i.e. relations to meta-beliefs (Tolliver 1982; Leite 2008).

4 To the extent that the kinds of meta-beliefs proposed by doxastic accounts are able to provide an explanation, they do so in virtue of their covariance with causal or counterfactual factors, but as we shall see with respect to Lehrer's example, the general consensus has been that these factors do not necessarily covary.

5 In the original case, the lawyer becomes aware of the line of reasoning proving his client's innocence after the Tarot reading. But it is an important and explicit feature of the original case that even after spotting the line of reasoning, the lawyer's emotional investment is such that if it weren't for the Tarot then he would still believe his client to be guilty despite seeing the line of reasoning that proves they can't be.
} 


\section{The peculiar case of Lehrer's lawyer}

Monday: There has been a string of eight murders. A serial killer has been shown to be guilty of the first seven murders, and is about to go on trial for the eighth. A lawyer is tasked with defending the accused of this final murder, however, the lawyer is very emotionally invested in the case and he has an overwhelming desire to believe that the murderer of all eight victims has been found. As a result he believes his client to be guilty (despite the lack of evidence either way).

Tuesday: The lawyer gets a call from a friend who works as a detective in the police department. They explain that they have realised that the accused couldn't be guilty of the eighth murder, since it was impossible for them to have gotten hold of the murder weapon in time. The lawyer is aware of the video footage and facts about the case on which this line of reasoning depends, and he sees that it entails that his client is innocent. However, given his emotional investment in the case, he still does not believe that his client is innocent, instead continuing to believe that he is guilty.

Wednesday: The lawyer is a superstitious man and regularly has a fortune-teller read the Tarot for him. Today the cards say that his current client is innocent. Given his strong faith in the power of the cards, he comes to believe that his client is innocent and goes on to defend him publicly by pointing out that he could not have gotten hold of the murder weapon (for exactly the reasons that the detective demonstrated to him on Tuesday).

Lehrer claims that on Wednesday the lawyer knows (and is justified in believing) that his client is innocent. If he is right then this spells serious trouble for causal and counterfactual accounts of the basing relation.

The problem is that in order for the lawyer's belief to be justified, and to be knowledge, it has to be based on the right reasons. In particular it has to be based on the line of reasoning which proves that his client could not have gotten hold of the murder weapon and therefore cannot be guilty of this final murder (and not just based on the bad reason that the Tarot cards have said that his client is innocent). But these good reasons aren't causally or counterfactually sustaining his belief: whether or not he is aware of the genuinely justifying line of reasoning has no effect on whether he believes his client to be guilty. His belief is instead causally sustained by, and counterfactually covaries with, the pronouncements of the fortune-teller: if the cards hadn't told him his client was innocent then he would not have believed it.

This implies that the basing relation cannot be a simple causal or counterfactual relation. ${ }^{6}$ The lawyer's belief is justified (and knowledge) and for that to be the case it must be based on good reasons, but the lawyer's belief is not causally or counterfactually related to the good reasons available in this case. The basing relation therefore cannot consist in a causal or counterfactual relation, but must instead consist in some other (non-causal, non-counterfactual) relation that holds between the lawyer's belief and the line of reasoning that proves his client's innocence.

\footnotetext{
6 Alternatively, one might conclude that basing is not required for justification, but given that we have here been assuming that basing just is whatever relation one has to bear to good reasons in order to count as justified or knowledgeable, that alternative isn't available.
} 


\section{The consequences of Lehrer's case}

Lehrer's case has had a profound impact on subsequent investigation into the basing relation. The case has been polarising. A number of commentators fail to share Lehrer's intuition that the lawyer's belief is justified, while others agree squarely with Lehrer that the lawyer's belief is justified and that he knows his client to be innocent. ${ }^{7}$

Those who agree with Lehrer's assessment of this case have either attempted to formulate increasingly complicated kinds of causal and counterfactual accounts of the basing relation which are compatible with the claim that the lawyer is justified, or else they have developed alternative doxastic accounts of the basing relation.

The complicated causal and counterfactual theories that have been proposed face the charge that they are simply ad hoc, involving an increasingly long list of (sometimes disjunctive) conditions which seem designed purely to avoid counterexample. ${ }^{8}$ (This kind of analysis is worryingly reminiscent of failed attempts to solve the Gettier problem.)

Alternative doxastic accounts, meanwhile, face their own problems. According to a basic doxastic account of the basing relation, a belief that $p$ is based on $b$ just in case one holds the higher-order belief that $\mathrm{b}$ is a good reason to believe that $\mathrm{p}$. There are two distinct concerns regarding this account of the basing relation. Firstly, it threatens to over-intellectualise epistemic basing such that infants and animals don't count as believing things on any basis whatsoever. And secondly, it fails to capture the sense in which the basis of a belief is what explains why one believes as one does. To the extent that the kinds of meta-beliefs proposed by doxastic accounts are able to provide an explanation, they do so in virtue of their covariance with causal or counterfactual factors, but the point of Lehrer's example is that these factors can come apart (since the lawyer recognises that the line of reasoning provides reason to believe even though there is no causal or counterfactual relation to his belief).

Meanwhile, those who disagree with Lehrer and maintain that the lawyer lacks justification and knowledge have continued to develop causal and counterfactual accounts of the basing relation which are not over-complicated or ad hoc. ${ }^{9}$ However, given that these accounts entail that Lehrer's lawyer lacks knowledge and justification, they are out of line with a significant portion of people's intuitions regarding the case and so (unsurprisingly) they have failed to gain widespread support.

In sum, Lehrer's lawyer presents a serious obstacle to attempts to analyse the epistemic basing relation. If one agrees with Lehrer that the lawyer knows that his client is innocent, then they are forced into endorsing either a highly complicated account of the basing relation, or a doxastic account according to which a subject's belief can be based on things which have nothing to do with why they believe as they do. And

\footnotetext{
7 Those who disagree with Lehrer include Goldman (1979), Swain (1981), Audi (1983), Pollock (1986), and Wedgwood (2006). Recent defenders of Lehrer's position on these cases include Bondy and Carter (forthcoming), Kvanvig (2003), and Korcz (2000).

8 See Swain's (1981) complicated causal plus pseudo-overdetermination account; the causal-doxastic theory in Korcz (2000) is similarly complicated; and more recently Bondy (2015) has suggested an even more complicated variation on the pseudo-overdetermination account.

9 See Wedgwood (2006), Turri (2011), McCain (2012), and Evans (2013).
} 
regardless of whether one agrees with Lehrer or not, no account of the basing relation can be widely accepted so long as this case continues to divide opinion.

My response to this bind is to downplay the importance of the case that Lehrer describes. It seems to me that it is very likely that Lehrer's lawyer is impossible, given what it is to hold the attitudes that he is described as holding. But even if he is metaphysically possible, the way that Lehrer describes his lawyer is certainly not psychologically plausible, i.e. human beings aren't like that and we know that they aren't. Given this, we can offer a simple diagnosis of the divergent intuitions that this case invokes: some intuitions about the case are being driven by responses to psychologically plausible readings of the case, and others to the psychologically implausible (or downright impossible) reading of the case which would be required in order for it to form a genuine counterexample. But insofar as these different intuitions are really about different cases, there is no problem in accounting for them both within the framework of simple causal or counterfactual accounts of the basing relation.

\section{The impossibility response}

Lehrer's lawyer is supposed to be a counterexample to causal and counterfactual accounts of the basing relation. But in order to work as a counterexample, it has to be a possible case. My preferred line of response is to claim that the case Lehrer describes is in fact a metaphysical impossibility.

According to the peculiar case of Lehrer's lawyer, on Tuesday the lawyer becomes aware of an argument which proves that his client is innocent, he accepts the premises of the argument, and he sees how it entails his client's innocence, and yet he fails to believe that his client is innocent (instead continuing to believe the opposite). This is clearly very odd. Lehrer aims to explain this oddity by stating that the lawyer is 'swayed by emotional factors' 10 into irrationally continuing to believe his client to be guilty. But does this idea pass muster? Can one really continue to believe the premises of an argument, see that it entails a conclusion, and still continue to believe the opposite? I am of the view that one cannot; that given the nature of belief and what it is to see that one thing follows from another, it is simply impossible for this situation to arise.

For instance, according to plausible views about the 'aim of belief,' truth is the (or a) constitutive aim of belief, ${ }^{11}$ i.e. anything that is not aiming at truth is simply not a belief (but rather some other kind of mental state). Of course there are questions surrounding the sense of 'aim' at issue, and the term 'belief' may be used more or less generously ${ }^{12}$ (so one might or might not limit beliefs to states which aim at truth in any substantial sense). For present purposes however we can specify the relevant claim as follows: it is plausible that the kind of belief-like mental state required for knowledge and justification is one which is truth oriented in at least the following sense-it is responsive to clear, demonstrative, evidence when it is recognised as such. Any mental

\footnotetext{
10 Lehrer (1971, p. 312).

11 See, e.g. Velleman (2000), Wedgwood (2002), Chan (2013), and Whiting (2014) for discussion.

12 See Stevenson (2002) for a taxonomy of different kinds of beliefs or belief-like states.
} 
state which does not meet this condition is just not the kind of state that is in the market for knowledge or justification.

But when Lehrer's lawyer continues to accept that his client is guilty while also accepting that there is evidence which proves the opposite, his attitude does not meet this condition and hence it cannot be a belief in the sense of foremost interest to epistemologists. (It must instead be something else, like a wishful thought or an alief, ${ }^{13}$ which is not the kind of thing that can be justified or knowledge.) Given what it is to believe (in the sense required for knowledge and justification), nobody could believe all of the things that Lehrer's lawyer is supposed to. ${ }^{14}$

Similarly, according to a species of inferential or conceptual role semantics like Peacocke's, ${ }^{15}$ in order to count as possessing certain concepts (like conjunction and disjunction), one has to find certain forms of inference compelling (e.g. conjunction elimination and disjunction introduction). Regardless of the broader ambitions of inferential role semantics, it certainly seems that the use of certain concepts requires a minimal competence with them (such as the cases of disjunction and conjunction). And the case of Lehrer's lawyer includes elements of this flavour. It seems impossible for the lawyer to really see that the line of reasoning entails his client's innocence if he continues to believe the premises and yet does not come to believe that his client was innocent. If he doesn't believe the conclusion then he hasn't really seen that it follows, since he has failed to be minimally competent with the concept of something following from something else in the way required to count as exercising that concept. Truly appreciating the evidential force of this argument just means coming to believe its conclusion (or else giving up one's beliefs in the premises). So if Lehrer's lawyer continues to believe that his client is guilty then he cannot have really appreciated the evidence like he is supposed to.

Imagine the lawyer telling his detective friend 'A and B are true, and I see that A and B entail that my client is definitely innocent, but my client is guilty (not innocent).' I am proposing that this is akin to claiming 'it's raining, but it's not true that it's raining' or 'it's raining, but I don't believe that it's raining.' It is not merely that you are irrational if you believe these things; you literally cannot believe them. Either this attitude is one which is not at all concerned with truth, so it is not a belief (at least not in the sense that matters when we are concerned with the possibility of knowledge and justification). Or else you have failed to grasp what it is for something to be true, what it is to believe something, or (in the present case) what it is for something to follow from something else, so spectacularly that your thoughts fail to be about truth, belief, and entailment at all.

If either kind of metaphysical claim is right, then the case that Lehrer describes is metaphysically impossible. Since impossibilities cannot be counterexamples, sim-

\footnotetext{
13 Gendler (2008) introduces aliefs, which are belief-like states that are unresponsive to evidence, and indeed belief, of their falsehood. (For instance despite believing that one is safe on a glass bridge, one may alieve that one is in danger; or despite believing that a sterilised bedpan is clean, one may alieve that it is unclean.)

14 I am indebted to Duncan Pritchard for suggesting this line of argument.

15 See Peacocke (1989) as well as Brandom (1994), Boghossian (2003), and Wedgwood (2007).
} 
ple causal and counterfactual accounts of the basing relation are back on the table. Moreover, there is a simple explanation for the divergent intuitions that people have had regarding the status of the lawyer's belief: intuitions that there is not knowledge are being driven by certain features that the case is specified to have (namely that there is not the right causal or counterfactual relation between the good evidence and the belief), and intuitions that there is knowledge are being driven by other features of the case (namely that the lawyer recognises the genuine line of reasoning; or that he genuinely believes, in a way concerned with trying to reach the truth, that his client is innocent-both facts which would entail that there is a causal or counterfactual relation between the lawyer's belief and good reasons for it). ${ }^{16}$ Both kinds of intuitions get things right in all possible cases, but this is not a possible case. $^{17}$

(Despite the impossibility of this case however, there are possible cases which are superficially similar and merely involve irrationality — as we will see shortly. The existence of actual cases like these may mislead us into supposing that Lehrer's impossible case is possible.)

\section{The implausibility response}

My preferred response is to claim that Lehrer's lawyer is impossible. This is strong medicine, it gets the job done but it requires signing up to some metaphysical claims which may not be to everyone's tastes. Perhaps some readers are of the view that it is possible to be spectacularly irrational: to still count as believing that $\mathrm{b}$ and seeing that $\mathrm{p}$ follows from $\mathrm{b}$, even while believing that not-p.

Even if you are not convinced that the lawyer case is impossible, I hope you will agree that understood literally it is psychologically highly implausible. Even if the lawyer described by Lehrer isn't a metaphysically impossible monster, he is still a very strange beast. He apparently believes in a way that I would wager no actual human being ever has. ${ }^{18}$

Of course, there are cases which are superficially similar. People are frequently irrational. But when people are irrational, they are irrational in far more subtle ways than Lehrer understands his lawyer as being. In fact, given just how implausible the case is when understood in the way required by Lehrer, I think that it should be considered ambiguous between this psychologically implausible interpretation (which Lehrer

\footnotetext{
16 Note what Goldman (1979) says in rejecting the verdict that there is justification in this case '...I find this example unconvincing. To the extent that I clearly imagine that the lawyer fixes his belief solely as a result of the cards [my emphasis], it seems intuitively wrong to say that he knows-or has a justified belief - that his client is innocent.'

17 Another upshot of this kind of impossibility response is that the kind of higher-order beliefs that doxastic accounts of the basing relation are concerned with (e.g. that b is a good reason to believe that $\mathrm{p}$ ) are sufficient for basing, since they also imply the right kind of causal/counterfactual relation.

18 Wallbridge (2016) also argues that the basing relation is typically treated in a way which ignores important psychological features. Although those issues are ignored here for simplicity, they are key to a fully adequate account of the basing relation, and to solving the generality problem.
} 
requires in order for the case to work as a counterexample to causal and counterfactual accounts of the basing relation) and more psychologically plausible interpretations.

Recall the situation in the middle of the case: the lawyer has before his mind the line of reasoning which demonstrates his client's innocence but (due to being 'swayed by emotional factors') he continues to believe that his client is innocent. I think that many of us would be inclined to interpret the situation so described as implying that the lawyer is 'in denial' about the innocence of his client, where this means that he knows (and believes) it really at some level of his psychology. (And merely has another belief-like attitude, such as a wishful thinking or an alief, to the opposite effect.) But note that, on this psychologically plausible rendering of the case, the lawyer's belief that his client is innocent is causally and counterfactually responsive to the evidence. Although it is initially repressed by his emotional investment in the case and only later unrepressed, he consistently believes that his client is innocent the entire time that he has evidence to that effect.

The lawyer is still irrational on this interpretation of the case, but his irrationality does not consist in not believing that his client is innocent, it consists in the way that his emotional investment in the case causes him to repress the belief that his client is innocent, and to have a delusion, wishful thought, or alief, that his client is guilty. Later on, when he consults the Tarot cards, this delusion, wishful thought, or alief is dispelled ${ }^{19}$ and the belief which was previously repressed then becomes explicit (it also has an additional basis, the say so of the Tarot cards, but the fact that the belief is over-based in this way does not prevent it from being justified or from being knowledge, given that it is also based on perfectly good reasons).

So the lawyer's attitudes towards his client's innocence are shaped by three forces. Firstly, there is the emotional investment which leads him to have the delusional wishful thought that his client is guilty, and which represses any beliefs to the contrary. Secondly, there is the justifying evidence which causes him to believe that his client is innocent (although this belief is initially repressed). And thirdly, there is the evidence of the Tarot which also causally sustains the belief that his client is innocent and, in addition, dispels delusions to the contrary, thus allowing this belief to be explicitly endorsed.

Depending on what combination of these three forces is present, the lawyer will have different wishful thinkings, repressed and explicit beliefs. But each factor has a distinct causal or counterfactual role. The emotional investment sustains a wishful delusion which represses any contrary beliefs; the Tarot cards sustain a belief and dispel any wishful delusions; and, most importantly, the evidence sustains a belief.

When the case is understood in this psychologically plausible way then, the claim that the lawyer knows his client is innocent is entirely compatible with simple causal or counterfactual accounts of the epistemic basing relation.

19 Of course, given the timeline in Lehrer's original presentation of the case, the lawyer only notices this evidence or line of argument after going back to the case once he has consulted the Tarot, but the psychological dynamics are essentially the same. There are two bases for his belief that his client is innocent (the good reasons and the bad reasons), and the Tarot cards also play an additional role in maintaining the explicitness of that belief/knowledge, given the emotional investment that he has in the case. 


\section{Other plausible renderings}

According to the peculiar case of Lehrer's lawyer, on Tuesday the lawyer becomes aware of an argument which proves that his client is innocent, he accepts the premises of the argument, and he sees how it entails his client's innocence, and yet he fails to believe that his client is innocent (instead continuing to believe the opposite). We have already seen how this is so odd that one might even think that it is impossible. But even if it is not impossible, it is not very psychologically plausible. On at least one much more plausible alternative (considered above) it turns out that the case presents no counterexample to causal or counterfactual accounts of the basing relation. However, there are still other psychologically plausible renderings of Lehrer's case, and it is worth investigating whether any of these present a counterexample.

In the case as originally presented by Lehrer, the lawyer only finds out about the line of reasoning that proves his client's innocence after he has already been convinced of their innocence by the Tarot cards, and hence there is no time at which the lawyer is both aware of the argument for his client's innocence and also believes them to be guilty. However, although this situation does not actually arise in Lehrer's original case, it is essential to his case that this situation could arise:

Indeed, and this is the crucial point, if it were not for his unshakable faith in the cards, the lawyer himself would be swayed by those emotional factors ... It is only because of his faith in the cards that the reasoning gives him knowledge. Therefore, the reasoning that gives him knowledge ... in no way supports or reinforces his belief, but it does give him knowledge. ${ }^{20}$

In rearranging the timeline of Lehrer's case as I have, I have been taking this passage to indicate that without his faith in the cards, the lawyer would continue to believe that his client is guilty (due to being 'swayed by emotional factors') despite still grasping the line of reasoning which proves him to be innocent. However, an alternative reading would be to interpret the claim that 'it is only because of his faith in the cards that the reasoning gives him knowledge' as meaning that without his faith in the cards, the lawyer would be unable to grasp the relevant line of reasoning and for that reason would simply fail to believe that his client is innocent. (This would be a very natural reading of Lehrer's case, given that he describes the line of reasoning as being 'very complicated, though completely valid.')

On such a reading, the case would involve a more psychologically plausible kind of irrationality whereby his emotional investment in the case leads him to fail to appreciate the force of the line of reasoning laid out by his detective friend, and to (deludedly) see it as misleading or insufficient. Or, in light of his emotional investment in the case, he might minimise cognitive dissonance by irrationally doubting or dismissing the premises of the argument (and only after the Tarot card reading come to appreciate the true evidential weight of the argument that his client is innocent).

The problem with these psychologically plausible renderings of the case, however, is that they cannot do the work that Lehrer requires because they don't present a

20 Lehrer (1971, p. 312). 
counterexample to causal or counterfactual accounts of the basing relation. On these interpretations, the lawyer believes his client to be innocent when he appreciates the true evidential weight of this line of reasoning and he believes him to be guilty otherwise. His appreciating the argument and accepting its premises is precisely what causes him to believe it's conclusion (it is just that whether or not he is in a position to appreciate these grounds varies in irrational ways); his belief therefore is causally and counterfactually related to his appreciating the line of reasoning which proves his client to be innocent in just the way required by causal and counterfactual accounts.

(And of course, the fact that he is required to have appreciated this line of reasoning, and not to doubt it, in order for it to causally or counterfactually support his belief is not a problem for causal or counterfactual accounts. The fact that such background conditions have to be met is perfectly mundane: Sherlock's belief that the butler is guilty varies causally and counterfactually in ways perfectly compatible with causal and counterfactual accounts of the basing relation despite the fact that there are possibilities - indeed actual times — at which he has the relevant evidence but he does not believe that the butler is guilty because he has not yet appreciated the relevant line of reasoning.)

In order for Lehrer's case to be capable of acting as a counterexample to causal of counterfactual accounts, the lawyer therefore has to be understood in a psychologically implausible (potentially impossible) way. And, as we shall see, this can help explain the competing intuitions that the case inspires.

\section{Intuitions and error theories}

The case of Lehrer's lawyer describes a psychologically highly implausible (or even flat out metaphysically impossible) kind of irrationality. However, the case is so implausible as to be ambiguous between the interpretation that Lehrer requires and alternative interpretations which involve a more psychologically plausible (or indeed, metaphysically possible) kind of irrationality. If the case is interpreted in one of these ways, then the lawyer's belief that his client is innocent is causally and counterfactually related to the good reasons that he has for this belief. Given this, there is a credible way to defend causal and counterfactual accounts of the basing relation from Lehrer's objection.

As the case is understood by Lehrer (or at least as it is required to be understood in order for his argument to work), the lawyer's beliefs really aren't responsive to the evidence, but only to the Tarot, and in this case the lawyer's beliefs are not based on the right kind of evidence so they are unjustified and not knowledge (contra Lehrer's claim). However, the lawyer in this case looks like he might be metaphysically impossible, and even if he isn't impossible, the way in which he accepts vaguely Moore-paradoxical claims ('these truths prove that $\mathrm{p}$, but not-p') is wildly implausible. This is very far removed from ordinary human psychology-even the irrational kind. On any more plausible rendering of the case (according to which the lawyer represses his beliefs, or dismisses or undervalues the evidence of his client's innocence) the lawyer's beliefs are responsive to the evidence. 
A simple error theory can then be invoked to explain the intuition that Lehrer's lawyer knows that his client is innocent: this intuition is being driven by interpreting the case in a psychologically plausible way, by exploiting the vagueness in Lehrer's presentation. Interpreted in such a way, the lawyer's beliefs are based on good reasons (but only because they are causally and counterfactually related to them). ${ }^{21}$

\section{Conclusion}

For a long time, the peculiar case of Lehrer's lawyer has stood in the way of attempts to understand the epistemic basing relation and prevented the possibility of any account meeting with general approval. I have aimed to remove this obstacle via a two track solution. For those willing to commit to certain plausible claims about the essentially truth-oriented nature of belief, or the minimal competence required to count as appreciating that $b$ entails $p$, the response to the case is swift: Lehrer's lawyer is impossible, therefore this case poses no counterexample to causal or counterfactual accounts of the basing relation.

For those who can't stomach the taste of this metaphysical medicine, there is another response: if the lawyer really does continue to appreciate the evidential force of the argument for his client's innocence throughout and doesn't harbour a repressed belief in his client's innocence, then he doesn't know that his client is innocent. But this lawyer is a strange beast and it is difficult to imagine such a psychologically implausible case. A much more plausible rendering of the case is one in which the lawyer's belief in his client's innocence is repressed, or he fails to appreciate the argument for his client's innocence, owing to his emotional investment in the case. In these versions of the case, the lawyer does end up knowing that his client is innocent, but only because his beliefs are causally or counterfactually sustained by good reasons. People's willingness to claim that the lawyer is justified can then be explained as a result of their intuitions tracking the more plausible readings of the case, as opposed to the case as Lehrer understands it, since his original presentation of the case left room for ambiguity. ${ }^{22}$

With Lehrer's counterexample thus dealt with, philosophers are free to get back to working on intuitive, well-motivated causal and counterfactual accounts of the basing relation without having to worry about being lawyered. Moreover, with the divergence of intuitions accounted for, there is now the possibility of reaching a broad consensus.

Next, in a final postscript, I will discuss how this treatment of Lehrer's case fits with a related case posed by Kvanvig.

\footnotetext{
21 A different tactic would be to point out that causal/counterfactual accounts of the basing relation are sufficient to capture epistemic basing as it actually occurs for human beings, and isn't that what we really care about? However, I suspect that many philosophers would be inclined to reply that this is not what they care about: that an account of the epistemic basing relation only captures what is important about epistemic basing if it applies to all possible cases, not just those that are possible given the contingencies of human psychology.

22 Again, it is instructive to recall what Goldman (1979) says, 'To the extent that I clearly imagine that the lawyer fixes his belief solely as a result of the cards [my emphasis], it seems intuitively wrong to say that he knows - or has a justified belief.'
} 


\section{Postscript, Kvanvig's Ill-motivated politician}

Interestingly, the basing relation does not seem to be limited to epistemology. The same relation (or at least a similar one) is important in practical reasoning: just as one's beliefs are only justified if they are based on good reasons, so too one's actions are only justified if they are based on good reasons. With this in mind, Kvanvig (2003) gives a case intended to parallel Lehrer's lawyer, but in the practical domain.

\section{Ill-motivated politician ${ }^{23}$}

Stage One: 'Jim is running for Congress, where this behavior is to be explained by an irrational desire to prove his critics wrong.' (Although he actually gives good reasons for his standing when questioned.)

Stage Two: 'Jim comes to realize his true motives. He has come to realize that the reasons he has given for running are not what brings him to run for Congress.' He realises that the reasons he previously gave for his behaviour (i) did not originally prompt the behaviour, (ii) have not, in the past, sustained the behaviour, and (iii) do not now sustain the behaviour (they do not even enhance the probability of his running, even controlling for the causal force of his irrational desire).

Stage Three: 'Upon confronting these rather disturbing facts, Jim then reasons as follows: "the inadequate motivations both past and present are regrettable and everything possible ought to be done to alter them; but, until this alteration can be accomplished, everything possible ought to be done to maintain some motivation or other to keep running for Congress since, after all, it is nonetheless true that I am extraordinarily good at convincing others of correct policy, that I am best qualified to serve the constituents of this district, and if persons were to attempt to quit doing everything which is done for inadequate reasons, not (as) much good would be done." So, Jim concludes, he ought to do all in his power to keep the race for Congress alive in spite of his bad motivations.'

Kvanvig claims that Jim makes rational progress during this course of events. In particular, Kvanvig claims that Jim makes significant rational progress during stage three and that the only kind of progress that he could count as making here is to move from 'performing a justified action to justifiably performing that action' ${ }^{24}$ In other words, his action (standing for Congress) comes to be based on the good reason that he would best serve his constituents. However, this is problematic for a causal account of the basing relation, since Jim's standing is not caused (or causally maintained) by this line of reasoning. Jim's action is in fact caused by his irrational desire to prove his critics wrong.

McCain (2012, 2014), offers three possible responses to Kvanvig's case: firstly, it is possible to deny that justification for belief and action are parallel in the way that Kvanvig suggests, and therefore the failure of a causal account of basing in the practical domain need not undermine the plausibility of a causal account of basing in the epistemic case. Secondly, McCain suggests that the rational progress Jim makes by formulating his reasoning in stage three could be accounted for without claiming that

\footnotetext{
23 Kvanvig (2003, pp. 50-51).

24 Kvanvig (2003, p. 61).
} 
he acts justifiably (in particular, he proposes that Jim comes to possess a reason such that were he to act on that basis then his action would be justified). And thirdly, he notes the possibility of denying that Jim has made any rational progress at all (at least when it comes to practical rationality) since his reasoning in fact has no impact on his actions.

I am very sympathetic to the second and third kind of response. However, it will be interesting to attempt to offer a treatment of this case which parallels the above treatment of Lehrer's lawyer.

The first line of response that I suggested to the case of Lehrer's lawyer was that, given certain plausible but not-uncontroversial assumptions, the case described is impossible - and the same is true of Kvanvig's politician. Jim is subject to akrasia, or weakness of will: he judges that the (all things considered) best thing for him to do is to stand for Congress and yet this does not lead him to stand (although it just so happens that other, irrational, factors do lead him to stand). However, akrasia has been thought by some (for instance Socrates in Protagoras or Hare 1952, 1963) to be impossible. Hence, just as one might think that Lehrer's lawyer is impossible because it is impossible to believe that there is demonstrative proof for $\mathrm{p}$ while believing $\mathrm{p}$ to be false, one might think that Kvanvig's politician is impossible because it is impossible to believe that an action is best (all things considered), and yet act differently. Moreover, one reason for holding this might be because one thinks that a bodily motion that is not in line with one's practical judgements is not an action (in the sense of interest), in parallel to the thought that a mental state that is not responsive to the admitted evidence is not a belief (in the sense of interest).

Of course these impossibility arguments require controversial metaphysical assumptions, but I also noted that even if Lehrer's lawyer isn't impossible, they are psychologically implausible — and the same can be said of Kvanvig's politician. Kvanvig states that at no stage in the proceedings do the good reasons even so much as increase the probability of Jim's standing (even once we control for his irrational desire), in other words Jim is subject to a kind of total akrasia. It is not just that what he recognises to be (all things considered) conclusive reasons for him to act are irrationally outcompeted by some other motivations or desires, but these reasons have literally no possible impact on how he acts. This is an odd kind of case, and not one that I think has ever actually occurred (I take it that in actual cases of akrasia, the recognised best course of action is in a position to play some motivating role, if it is not swamped by other irrational urges).

If we were to recast Kvanvig's case such that Jim's akrasia was of some more normal, non-total, kind then Jim could easily be seen to be making rational progress. Jim's coming to see the real value in what were previously only empty words to him (e.g. 'I am best placed to alleviate the suffering of the constituents') would provide some degree of causal support to his standing (even if not enough to actually overcome akrasia and so lead to action), and this would lead to progress by bringing him closer to a situation in which his action is based on good reasons.

Unfortunately, even though this more psychologically plausible rendering of Kvanvig's case is compatible with a causal account of the basing relation, this fact cannot be used to explain any divergent intuitions (as I proposed with the case of Lehrer's lawyer), since Kvanvig is explicit on this point (not ambiguous like Lehrer). However, it is also not clear that this case provokes any divide in intuitions which would require 
explanation. I personally fail to share Kvanvig's intuitions, and there are not (to my knowledge) any published responses to the case which agree with Kvanvig, while (McCain 2012, 2014) is very willing to deny that Jim acts justifiably. I will leave readers to consult their own intuitions, but if I am right then given that Kvanvig's case is tightly described so as to make it entirely clear that there is no kind of causal or counterfactual connection whatsoever, the case just fails to inspire the intuition that Jim acts justifiably.

Open Access This article is distributed under the terms of the Creative Commons Attribution 4.0 International License (http://creativecommons.org/licenses/by/4.0/), which permits unrestricted use, distribution, and reproduction in any medium, provided you give appropriate credit to the original author(s) and the source, provide a link to the Creative Commons license, and indicate if changes were made.

\section{References}

Audi, R. (1983). The causal structure of indirect justification. Journal of Philosophy, 80(7), 398-415.

Boghossian, P. (2003). Blind reasoning. Aristotelian Society Supplementary, 77(1), 225-248.

Bondy, P. (2015). Counterfactuals and epistemic basing relations. Pacific Philosophical Quarterly, 96(4)

Brandom, R. B. (1994). Making it explicit: Reasoning, representing, and discursive commitment. Cambridge: Harvard University Press.

Carter, A., Bondy, P. (forthcoming). The basing relation and the impossibility of the debasing demon. American Philosophical Quarterly.

Chan, T. (2013). The aim of belief. Oxford: Oxford University Press.

Conee, R. F. E. (1985). Evidentialism. Philosophical Studies, 48(1), 15-34.

Evans, I. (2013). The problem of the basing relation. Synthese, 190(14), 2943-2957.

Firth, R. (1978). Are epistemic concepts reducible to ethical concepts? In A. G. \& J. Kim (Eds.), Values and morals: Essays in honor of William Frankena, Charles Stevenson, and Richard Brandt (pp. 215-229). Dordrecht: Kluwer.

Gendler, T. S. (2008). Alief and belief. Journal of Philosophy, 105(10), 634-663.

Goldman, A. (1979). What is justified belief? In G. Pappas (Ed.), Justification and knowledge (pp. 1-25). Boston: D. Reidel.

Hare, R. M. (1952). The language of morals. Oxford: Clarendon Press.

Hare, R. M. (1963). Freedom and reason. Oxford: Clarendon Press.

Korcz, K. A. (2000). The causal-doxastic theory of the basing relation. Canadian Journal of Philosophy, 30(4), 525-550.

Kvanvig, J. L. (2003). Justification and proper basing. In E. Olsson (Ed.), The epistemology of Keith Lehrer (pp. 43-62). Dordrecht: Kluwer Publishing Co.

Lehrer, K. (1971). How reasons give us knowledge, or the case of the Gypsy Lawyer. Journal of Philosophy, 68(10), 311-313.

Leite, A. (2008). Believing one's reasons are good. Synthese, 161(3), 419-441.

McCain, K. (2012). The interventionist account of causation and the basing relation. Philosophical Studies, 159(3), 357-382.

McCain, K. (2014). Evidentialism and epistemic justification. New York: Routledge.

Moser, P. K. (1989). Knowledge and evidence. Cambridge: Cambridge University Press.

Peacocke, C. (1989). Possession conditions: A focal point for theories of concepts. Mind and Language, $4(1-2), 51-56$.

Pollock, J. L. (1986). Contemporary theories of knowledge. London: Hutchinson.

Stevenson, L. F. (2002). Six levels of mentality. Philosophical Explorations, 5(2), 105-124.

Swain, M. (1981). Reasons and knowledge. Ithaca: Cornell University Press.

Tolliver, J. (1982). Basing beliefs on reasons. Grazer Philosophische Studien, 15, 149-161.

Turri, J. (2011). Believing for a reason. Erkenntnis, 74(3), 383-397.

Velleman, D. (2000). On the aim of belief. In D. Velleman (Ed.), The possibility of practical reason (pp. 244-281). Oxford: Oxford University Press. 
Wallbridge, K. (2016). Solving the current generality problem. Logos \& Episteme, VII(3), 345-350.

Wedgwood, R. (2002). The aim of belief. Philosophical Perspectives, 36(s16), 267-297.

Wedgwood, R. (2006). The normative force of reasoning. Noûs, 40(4), 660-686.

Wedgwood, R. (2007). The nature of normativity. Oxford: Oxford University Press.

Whiting, D. (2014). Reasons for belief, reasons for action, the aim of belief, and the aim of action. In C. Littlejohn \& J. Turri (Eds.), Epistemic norms. Oxford: Oxford University Press. 